\title{
Land Use-Land Cover Change and Drivers of Deforestation in the Patako Protected Area (Center-West of Senegal)
}

\author{
Simon Sambou ${ }^{1}$, Anne Mette Lykke ${ }^{2}$, Hyacinthe Sambou ${ }^{1,3}$, Idrissa Guiro ${ }^{1}$, Bienvenu Sambou ${ }^{1}$, \\ Cheikh Mbow $1,3,4$ \\ ${ }^{1}$ Institute of Environmental Sciences, Faculty of Sciences and Technology, Cheikh Anta Diop University of Dakar. Dakar Fann, Senegal \\ ${ }^{2}$ Department of Biological sciences, Aarhus University, Vejlsovej, Silkeborg, Denmark \\ ${ }^{3}$ Laboratory of Teaching and Research in Geomatics, Polytechnic High School, Cheikh Anta Diop University of Dakar, Dakar-Fann, Sénégal \\ ${ }^{4}$ World Agroforestry Centre (ICRAF), Nairobi, Kenya
}

Email address:

sambousimon@gmail.com (S. Sambou)

\section{To cite this article:}

Simon Sambou, Anne Mette Lykke, Hyacinthe Sambou, Idrissa Guiro, Bienvenu Sambou, Cheikh Mbow. Land Use-Land Cover Change and Drivers of Deforestation in the Patako Protected Area (Center-West of Senegal). American Journal of Environmental Protection.

Vol. 4, No. 6, 2015, pp. 306-317. doi: 10.11648/j.ajep.20150406.17

\begin{abstract}
This study focus on land use-land cover changes relation to the multidimensional characteristics of spatial and temporal patterns of land dynamics and social practices. The objectives are to characterize the dynamics of land-use and landcover changes from 1992 to 2015, and to identify the drivers of deforestation and land degradation. Nine (09) types of classes were identified: humid vegetation (HV), savanna/wooded savanna (WS), savanna/shrub savanna (SSS), shrub savanna (SS), mangrove (MA), grass savanna (GS), cropland (CP), water (WA), and bare soil (BS). The process of change was analysed within a 5614.6 ha which includes the Patako protected area. The results have shown significant changes in land use-land cover for more than two decades (1992 to 2015). A high variability of land cover transfer was recorded between periods and class categories. At least, $55 \%$ of the HV changed to WS that was manifested by a loss of $16 \%$ during the first decade. The most important decline in area was recorded annually within the HV (4.8\%), and the WS (2.6\%), while the SSS experienced a substantial annual increase of $0.5 \%$. The appearance of the SS (10.3\%), during the last fifteen years, is a witness to degradation process as a result of anthropogenic pressure mainly for subsistence raisons. This pressure resulted to a conversion of small forested land to agricultural land on the boundary of the protected area. Tree cover represented $99.4 \%$ of the entire forest area in $1992,97.4 \%$ in 2010 , and slightly more $(+1.2 \%)$ in 2015 . According to this evolution, the annual rate of deforestation was estimated to $0.09 \%$ with an average of $0.11 \pm 0.08 \%$ for the three defined periods. The drivers leading to changes in land useland cover stresses the complexity that is related to sustainable management of protected areas. Urgent action is necessary to reduce loss of biodiversity due to deforestation and land degradation. For this purpose, a particular attention must be paid to the implementation of the Patako management plan under a Reducing Emissions from Deforestation and Forest Degradation (REDD+) project.
\end{abstract}

Keywords: Land Use Change, Savanna, Saloum Delta, West Africa

\section{Introduction}

Livelihoods and productive systems in African countries are highly related to vegetation changes [1, 2-3]. Gathering landscape scale information to assess land use types, their evolution and deforestation rate requires earth observation methods that allow for large spatial coverage and historical tracking of spatial dynamics $[4,5]$. The use of remote sensing enables better design of management plans and thereby improved management of forest resources [6]. Various applied remote sensing methods exist, but despite real progress in applied remote sensing, big challenges are faced in connecting maps with drivers of land use change. The link between image outputs and casual factors of change is sometimes fuzzy, nonlinear or incidental and requires steady disaggregated information on local human practices. Additionally, there is many intertwined connections between drivers with cascade effects that make it difficult to singleout individual factors. In many reports, the most described drivers are forest fires [7, 1-8, 9-10], pasture, farming land 
extension, fuelwood and timber extraction.

In this context, reversal of land degradation in semi-arid zones requires a clear understanding of the synergetic effect of natural and socio-economic factors [11]. Several studies described these complex dynamics of land use-land cover change in savanna ecosystems of Senegal, e.g. in the groundnut cultivation zone [12]. The rapid development of groundnut production and the subsequent economic crisis and migration are significant causes of change [13]. Natural vegetation has been replaced by farm lands, where trees have been eliminated because of farming techniques and agronomist approaches that aim at modern intensification.

The conversion of forests to agricultural land and/or pasture induce in short and medium terms significant decrease in carbon stock, thereby promoting an increase in $\mathrm{CO}_{2}$ emissions in the atmosphere. Under UNDESERT (understanding and combating desertification to mitigate its impact on ecosystem services) program, a particular emphasis was given to the restoration of degraded lands, restoration of biodiversity and increasing carbon sequestration. A buffer zone has been created to mitigate population impact on Patako protected forest and several activities such as forestry and agroforestry have been implemented. Therefore understanding of drivers that lead to deforestation at local scale is essential for designing these interventions and develop best policies and measures. Addressing the drivers is also important as strengthening the conservation of forests and its resources are an important part of the development objectives of Senegal. This study focus on land use-land cover changes relation to the multidimensional characteristics of spatial and temporal patterns of land dynamics and social practices. The objectives are to characterize the dynamics of land-use and land-cover changes from 1992 to 2015 in a protected area, and to identify the drivers of deforestation and land degradation.

\section{Material and Methods}

\subsection{Description of the Study Area}

The study was conducted in Patako protected area and its surrounding agricultural areas in the center-west of Senegal $\left(13^{\circ} 40^{\prime} 59.59^{\prime \prime} \mathrm{N}\right.$ and $\left.16^{\circ} 15^{\prime} 59.88^{\prime} \mathrm{W}\right)$. Patako covers about 5614.6 hectares and was classified as a protected area in 1934. Patako was originally a tropical dry forest, but has changed into savanna mainly because of human impact such as fire and cutting. The vegetation has changed within the last 80 years.

The precipitation $(600-800 \mathrm{~mm})$ is unimodal with a short rainy season from June to October (4-5 months) and a dry season from October to May (8-9 months) [13]. The interannual variability is high ranging from $562 \mathrm{~mm}$ to 813 $\mathrm{mm}$ within the last 10 years. Mean annual temperature is $26.58^{\circ} \mathrm{C}$.

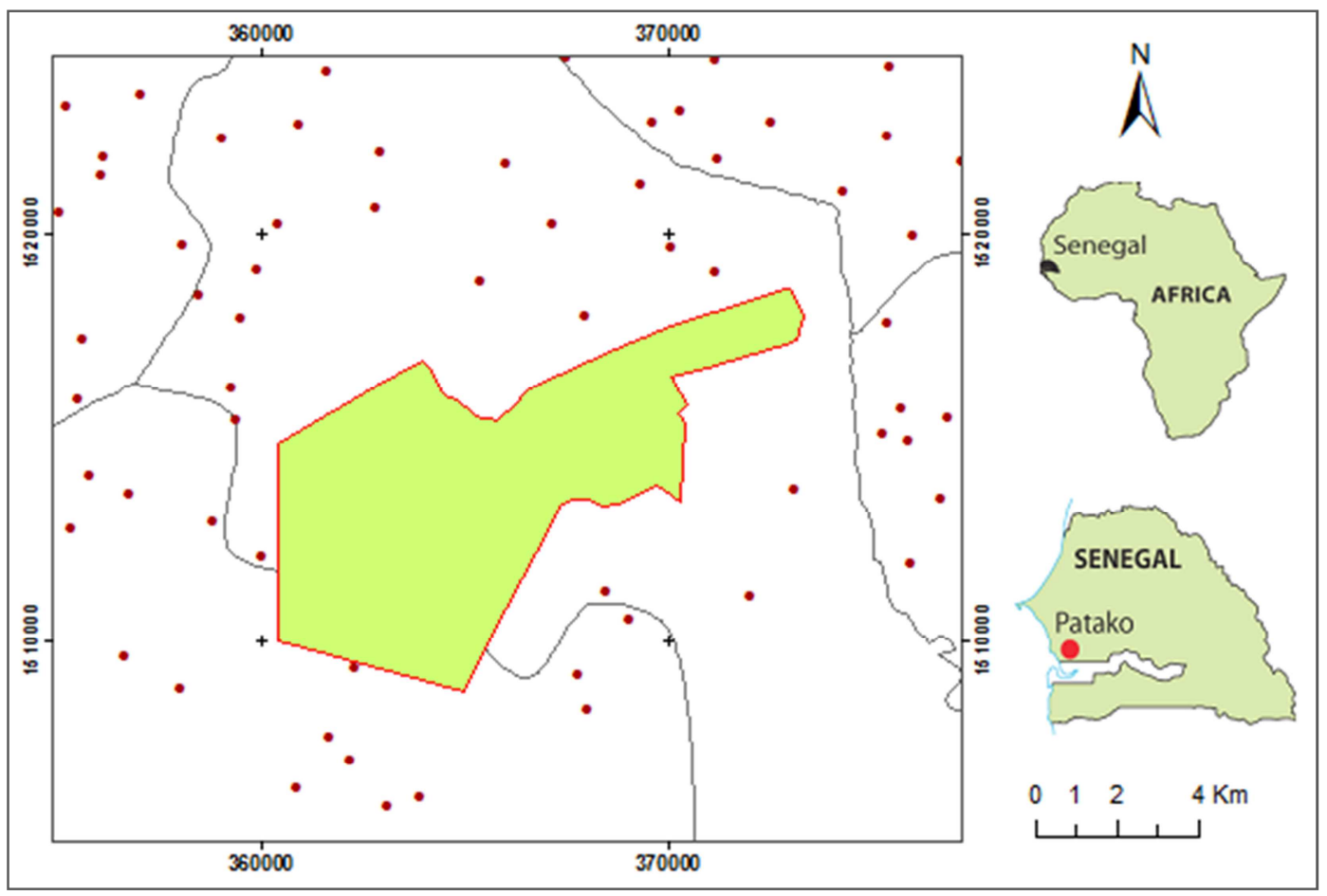

Figure 1. Location of the study area. Red dots represent villages and red line is the border of the protected area in green.

The area is dominated by ferruginous tropical soils, poorly evolved soils, hydromorphic soils on alluvial plains and gleysalted soils along valleys. Croplands with groundnuts, millet and maize occupy vast spaces, with mosaics of other land use- land cover types, mainly savannas, plantations of Anacardium occidentale, humid vegetation and vegetable gardens. There is a sharp border between the agrosystem with open cultivated land and the protected area. The agricultural lands have an 
average density of less than 2 trees/ha (range from 0 to 4 trees/ ha) and a deforestation rate of $3 \%$ per year [14].

\subsection{Satellite Data Used}

The whole area is covered by the Landsat scene (Path 205, Rows 50) for each of relevant dates. The selected images are acquired in the same period of the year during the dry season to reduce problems related to phrenology change in vegetation (exaggeration of the herbaceous plant cover) and soil humidity difference. The advantage of this period is to have a low cloud cover. Thus, the images used are: an old cover TM of 5 March 1992, ETM + of January 9, 2001 and December 28, 2010 and a recent Landsat 8 OLI (Operational Land Imager) of January 9, 2015. All images were taken from the database of the United State Geological Survey (USGS).

\subsubsection{Images Processing and Classification}

The first step of image processing was the visual analysis. It corresponds to a visual interpretation, ie the application of the conventional method of photo-interpretation to satellite image. This method involves identifying the different homogenous units [15]. The interpretation was often facilitated by knowledge of the study area and field surveys. The images used for this study were already georeferenced (UTM WGS 84), with radiometric corrections and did not need geometric corrections. In order to avoid mismatches due to difference in the Landsat sensors and optimize the superposition of images for diachronic analysis, the data from 1992, 2001 and 2010 were orthorectified in reference to 2015 on the basis of seamarks points. The images were mosaicked and a smoothing of the dynamic performed. In order to harmonize and facilitate the superposition of images for diachronic analysis, the image of 1992 and 2001 have been readjusted compared to that of 2015. The wedging error $(\mathrm{RMS}=0.124)$ is less than a Landsat pixel.

After wedging images, we created colored compositions by combining channels 5 for infrared [0.75-0.90 $\mu \mathrm{m}], 4$ for red $[0.63$ to $0.69 \mu \mathrm{m}]$ and 3 for green $[0.52$ to $0.60 \mu \mathrm{m}]$. In the colorimetric order red, green, blue were chosen for the images 1992, 2001 and 2010. As for the image 2015, the channels 6 for infrared [1.560 to $1.660 \mu \mathrm{m}$ ], 5 for red [0.845 $-0.885 \mu \mathrm{m}]$ and 4 for green [0.630 to $0.680 \mu \mathrm{m}$ ] were chosen. On this basis the study area was extracted in order to quantify the land use and its evolution over time.

The supervised classification method by maximum likelihood was used for all images. The choice of this method can be explained by the heterogeneity of land use in the study area and the probability of confusion for some components, namely bare soil and tans. The hierarchical classification starts with the determination of the number of classes and the choice of training plots to achieve a cartographic synthesis through successive selections of the best classified elements. The determination of the number of classes is based on the clustering performed upstream and information gathered in the field.

Furthermore, to eliminate isolated pixels or small unclassified areas and to homogenize the results of the thematic classification a filter of $3 \times 3$ pixels was applied from majority analysis. To check the validity and performance of the classifications, witness areas as well as reference data were collected in the field. The selected classes were also confronted with exogenous documents that provided information on the type of land use. These documents are thematic and synthesis maps. The analysis of the colored compositions allowed to identify at least nine (09) classes interpreted using the following abbreviation codes: humid vegetation (HV), savanna/wooded savanna (WS), savanna/shrub savanna (SSS), shrub savanna (SS), mangrove (MA), grass savanna (GS), cropland (CP), water (WA), and bare soil (BS). The type of vegetation was defined in the basis of the nomenclature of Yangambi [16] modified by [17].

\subsubsection{Land Use-Land Cover Change Analysis}

The result obtained from the supervised classification was exported to vector format in ARC GIS software. This transfer of map files helped to complete the processing and analysis of images and produce land use land cover maps. Changes detection were perform based on these maps. The crossing of the 1992-2001, 2001-2010 and 2010-2015 land use-land cover maps allowed to establish the maps of change. This cross was made based on classes' codification and a code comparison between two maps. Statistics of detected changes were computed by comparing image class shifts between the four images 1992, 2001, 2010 and 2015.

The trends of changes were calculated based on typical rate of land cover transition for each category. Transition intensities were estimated relatively to the size of a land cover class in the initial year to its size in the subsequent year. These changes can be positive (increase or perspective of gains) or negative (decrease or perspective of losses). Three situations have been observed and taken into account in the analysis (e.g. land cover stability, conversion and modification). Land cover stability refers to all classes that have not been affected by changes during the studied period. The changes was expressed as conversion and/or modification. By conversion, we mean the transition from one category to another (e.g. from woodland to cropland), while modification represents a change within one land use or land cover category $[18,19]$ due to changes in its physical or functional attributes (e.g. from savana to shrub savana to degraded savana). Matrices of land use-land cover transfer was generated using changes from one layer to another.

\subsubsection{Annual Rate of Deforestation}

Deforestation is explained as a conversion of forested areas to nonforest land use. This type of degradation notify a reduction of forest quality and a decrease of its overall cover due to native forest land clearing for different purposes [20]. The annual rate of deforestation was calculated by comparing the area under forest cover at two different times. The period covered in estimating the rate of deforestation is from 1992 to 2015. Different methods have been used to estimate the annual rate of change. But in order to standardize the 
methods and avoid confusion, [21] devised a new formula which is used in the context of this study:

$$
\text { Rate }=\left(\frac{1}{t_{2}-t_{1}}\right) \ln \left(\frac{S_{2}}{S_{1}}\right)
$$

where $S_{I}$ is the class area at the initial time $\left(t_{1}\right)$ and $S_{2}$ is the class area at the final time $\left(t_{2}\right)$ according to the land use-land cover maps.

\subsection{Drivers of Deforestation}

Characterizing the drivers of deforestation first involve their identification and grouping in different categories. We identified two main drivers (direct and indirect) which were divided into two categories. The direct drivers concerned natural effects that includes climate variability and change, flood and parasitic attack. The direct anthropogenic drivers are actions or factors that directly impact forest cover. They are considered as subsistence drivers. The indirect or underlying drivers of deforestation are complex interactions of demographic, economic, cultural and institutional that in combination intensify direct human causes. Semi-structured interviews were conducted with resource people for three target groups of local stakeholders (local population, local authorities and local technical staff of forest service). The interviewees were selected from 6 villages located in a 0-3 $\mathrm{km}$ radius around the protected area to help better understand the complexity of the drivers. Furthermore, on the basis of field knowledge observations were made into and outside Patako protected area for triangulating the obtained information.

\section{Results}

\subsection{Land Use-Land Cover from 1992 to 2015}

The land use-land cover maps show that three characteristic classes were dominant during the studied period (1992-2015). These classes related to the CP in the periphery, the SSS and the WS in the Patako protected area. The land cover is highly dynamic (Table 1). In 1992, the periphery of the protected area was covered by a mixture of $\mathrm{CP}$ and SSS. Within the protected area the SSS represented (56.6\%) while the WS and the HV occupied respectively $28.1 \%$ and $14.5 \%$. A significant difference was observed between the latter and the rest of classes (WA, GS, CP and BS) as totaling less than $1 \%$. These classes have increased slightly (1.2\%) nine years after (in 2001). As for the WS a substantial increase of its size was observed $(51.1 \%)$ at the expense of the SSS (44.3\%) and the HV (3.4\%). In opposition to the protected area the periphery was highly deforested and substituted to agricultural lands.

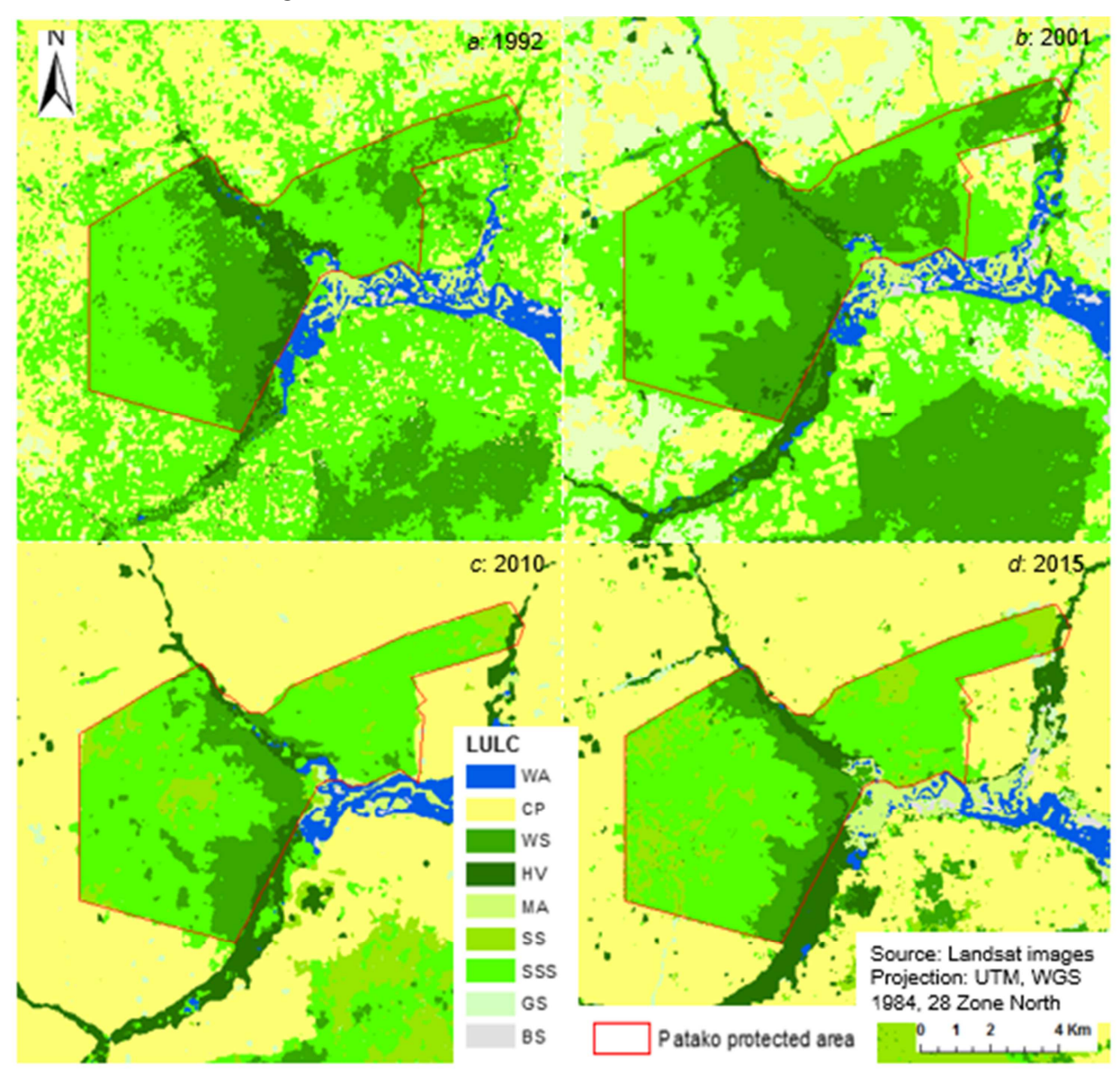

Figure 2. Land use-land cover in Patako protected area and its periphery. 
Table 1. Dynamics of land use-land cover in Patako Forest.

\begin{tabular}{|c|c|c|c|c|c|c|c|c|c|}
\hline \multirow{2}{*}{ Code } & \multirow{2}{*}{ LULC classes } & \multicolumn{2}{|l|}{1992} & \multicolumn{2}{|l|}{2001} & \multicolumn{2}{|l|}{2010} & \multicolumn{2}{|l|}{2015} \\
\hline & & ha & $\%$ & Ha & $\%$ & ha & $\%$ & $\mathbf{H a}$ & $\%$ \\
\hline HV & Humid vegetation & 812.3 & 14.5 & 191.4 & 3.4 & 195.3 & 3.5 & 269.5 & 4.8 \\
\hline WS & Woodland to wooded Savanna & 1578.3 & 28.1 & 2869.5 & 51.1 & 1091.9 & 19.4 & 844.1 & 15.0 \\
\hline SSS & Savanna to shrub savanna & 3177.9 & 56.6 & 2489.5 & 44.3 & 3688.4 & 65.7 & 3603.1 & 64.2 \\
\hline SS & Shrub savanna & 0 & 0.0 & 0 & 0.0 & 473.3 & 8.4 & 796.2 & 14.2 \\
\hline MA & Mangrove & 9.9 & 0.2 & 14.0 & 0.3 & 19.6 & 0.3 & 21.0 & 0.4 \\
\hline GS & Grass savanna & 1.0 & 0.0 & 4.6 & 0.1 & 10.4 & 0.2 & 2.9 & 0.1 \\
\hline $\mathrm{CP}$ & Cropland & 5.3 & 0.1 & 23.9 & 0.4 & 94.6 & 1.7 & 47.9 & 0.9 \\
\hline BS & Bare soil & 0 & 0.0 & 0 & 0.0 & 0 & 0.0 & 0.5 & 0.0 \\
\hline Total & & 5614.6 & 100 & 5614.6 & 100 & 5614.6 & 100 & 5614.6 & 100 \\
\hline
\end{tabular}

In 2010 there is almost an elimination of the SSS in the periphery. Within the protected area the latter class cover remained the most significant type $(65.7 \%)$. Therefore the WS and the HV covered respectively $19.4 \%$ and $3.5 \%$. Marginal classes covered a total of $2.9 \%$ of the area of the protected area, an increase of more than $41 \%$ compared to 2001. Between 2001 and 2010, we noted the emergence of a new class, the SS representing (8.4\%). It results from the fragmentation of the SSS and generally located in the center and north-eastern parts (Figure $2 \mathrm{c}$ ).

Concerning 2015 there are some increase in land cover for many classes compared to 2001 and 2010 (Figure 2d). The SSS remained the most significant class $(64.2 \%)$ despite the fragmentation it undergoes and which causes the increase of the SS $(14.1 \%)$. This relative extension came at the expense of the WS $(15.3 \%)$. The MA was characterized by a mean increase of $0.3 \%$ ranging from $0.2 \%$ to $0.4 \%$ between 1992 and 2015. This is also the case of the CP which substantially increased for 5 to 95 ha between 1992 in 2010 before decreasing to 48 ha in 2015. Other land cover (WA, GS, etc.) were poorly represented inside the protected area.

\subsection{Land Use-Land Cover Change Analysis}

Results from LULCC showed significant changes in land use and land cover. Between 1992 and 2001, many land use were converted to other types in the agrosystem. These changes affected mostly the SSS and GS (Figure 3a, b) and processes of change continued to occur during the period 2001-2010. Between 2010 and 2015 (Figure 3c) the agrosystem became more stable due to the almost total use of farmland resulting in a scarcity of fallows. As the changes in the agricultural lands were unidirectional we focused the analysis within the protected area.

Regarding the land use-land cover transfer between class categories it was found that generally modification was more important in term of frequency within the Patako protected area. This type of change affected mostly the HV from 1992 to 2001 . At least $83 \%$ of its area moved to WS. The latter moved for $31.6 \%$ to the SSS and inversely for $36.9 \%$. For this, a stability of $64.6 \%$ and $62.3 \%$ was respectively observed for these classes. Concerning the conversion the most important land use-land cover transfer was found in the $\mathrm{CP}$ and GS. More than $56.6 \%$ moved from the CP to GS and in the opposite direction $91.4 \%$.

From 2001 to 2010 the HV became more stable (67.3\%) compared to the first period. An average modification $(19.3 \%)$ was observed towards the WS. This latter was the class that decreased in favor of the SSS (58.5\%). This transfer caused a progressive shrinking of the class cover. As for the conversion it was characterized mainly by the GS which stability had become quasi null. $25.8 \%$ of the CP was abandoned and replaced by the SSS. Changes from vegetation cover to small classes (WA, GS, GS and CP) was generally weak (less than $10 \%$ ) but the transfer in the opposite direction was more significant despite the good stability $(60.4 \%)$ of the CP.

From 2010 to 2015 the stability of some land use-land cover classes is rather good ( $>50 \%$ ) compared to others like the GS (3.4\%). The vegetation cover modification affected more the WS and the SS which areas were respectively transfered towards the SSS for more than 36\% and the 54\%. The results from the matrix of land use-land cover transfer reveal that conversions were mainly observed in the GS and the CP. Despite its small area $54.5 \%$ of the GS was converted to SS while $18 \%, 12 \%$ change respectively towards the CP and the SSS. These changes explain the low stability of that class. As for the cultuvated land more than 35\% were converted to the SSS and $15 \%$ to the SS.

When we consider the matrix of land use-land cover transfer from the overall period of study (1992 to 2015) we note that the HV and the WS experienced a low stability. For the first class at least 55\% was modified to WS and $18 \%$ to SSS. For the second one the major modification took place towards the SSS as representing 72.2\%. The transfer of area from the SSS towards the SS was done gradually going from $12.6 \%$ in 2010 to $14.9 \%$ in 2015 with an average of $20.2 \%$ between 1992 and 2015. It is also important to note that the intrusion of the arable lands generally took place in the border between the protected area and the agricultural zone especially where the farmers do not have a precise reference mark of delimitation.

Several changes occurred within the protected area (Figure 4). The most important decline in vegetation cover were held from 1992 to 2001 in the HV (16.0\%). We also noted a substantial decline in the same period for the SSS (2.7\%) while the WS experienced a gain of $6.6 \%$. By cons, it 
recorded a loss of $10 \%$ of its area between 2001 and 2010 and $4.8 \%$ between 2010 and 2015 . During the last period, substantial losses $(0.4 \%)$ have been also demonstrated in the SSS. This decline was offset by a gain in area in the SS $(10.3 \%)$. Globally the rate of change corresponding to these types showed a deline of $4.8 \% \mathrm{yr}^{-1}$ in HV and $2.6 \% \mathrm{yr}^{-1}$ in the WS, while the SSS recorded an extension of its area during the study period (1992-2015). Regarding the dynamics, MA stand out with significative changes. However, one of the most disturbing change was the influence of the agricultural zone of the protected area. Between 1992 and 2010, the CP experienced an increase of $16.3 \%$ before declining to $13.8 \%$ for the last five years (2010 and 2015).
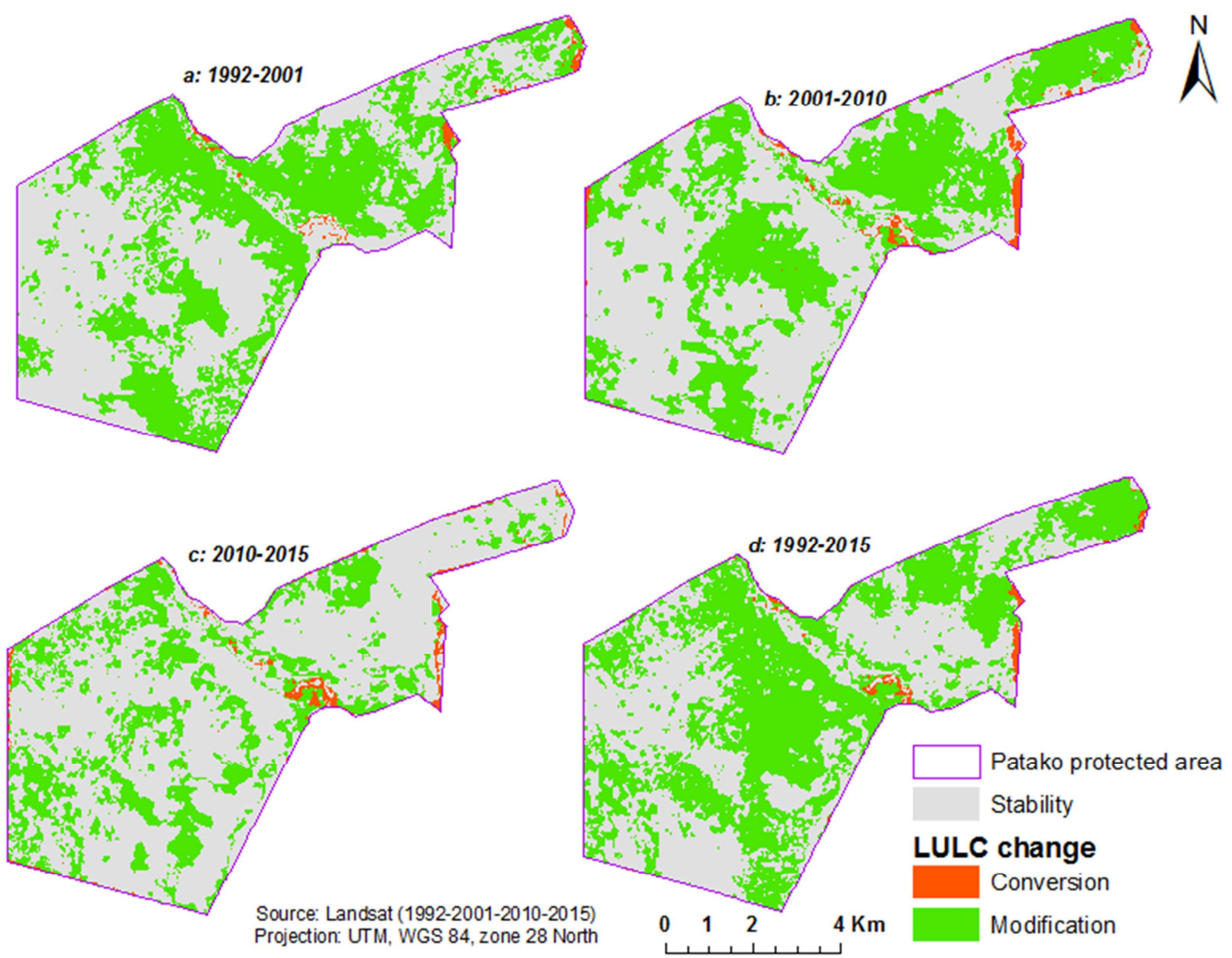

Figure 3. LULCC in Patako area from 1992 to 2015.

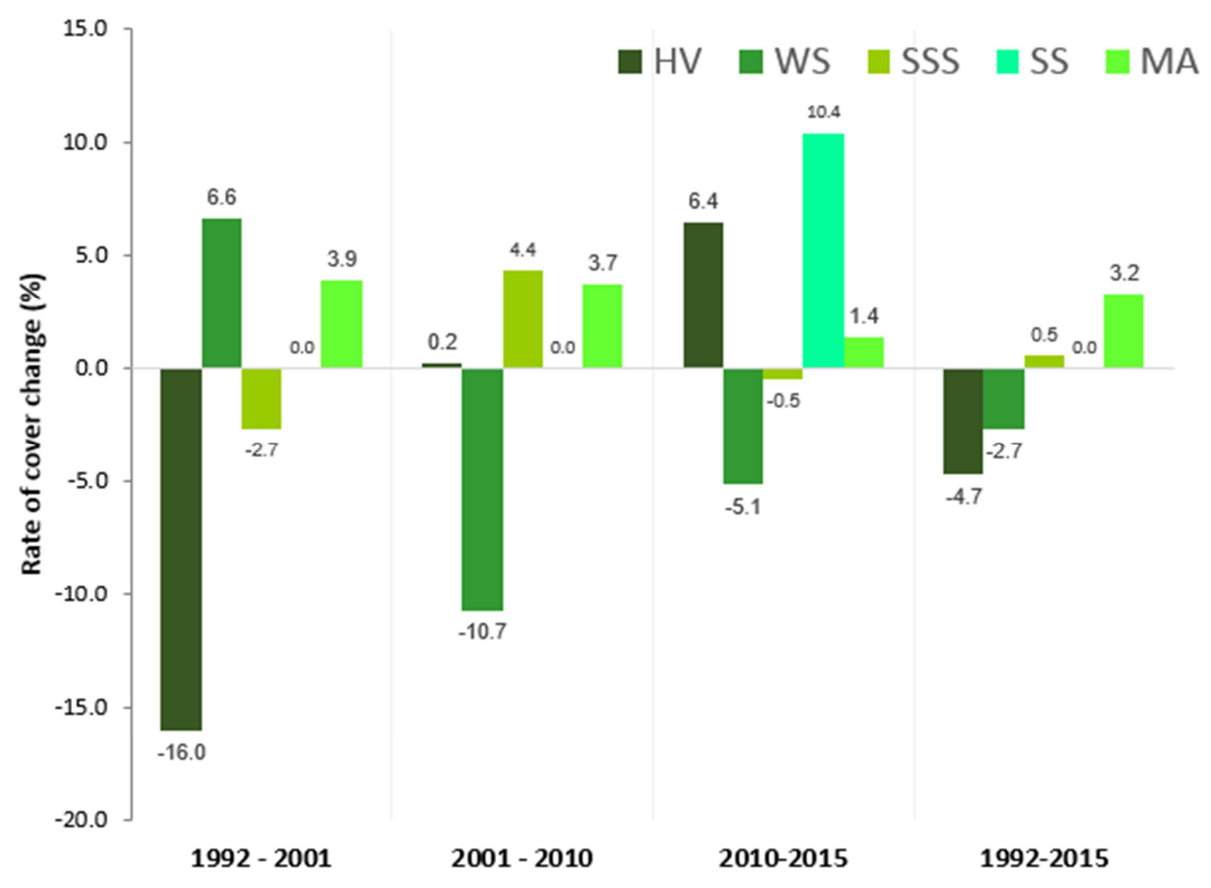

Figure 4. Rate of cover change in Patako protected area. 


\subsection{Rate of Deforestation}

Deforestation is the process by which forested land is replaced by another type of non-forested land, for example agricultural land. The total area of the Patako protected forest is estimated to 5614.6 ha. The conversion of forested land in this area is mainly connected with small-scale shifting agriculture or land clearing by sedentary landholders who want to expand their crop.

Taking into account the vegetation cover an annual rate of deforestation was estimated. The forested area decreased slightly during the study period. It covered 5578.4 ha $(99.4 \%)$ in $1992,5564.5$ ha $(99.1 \%)$ in 2001 and 5468.5 ha (97.4\%) in 2010. In 2015 a slight increase (1.2\%) was recorded compared to the coverage of 2010.

The results showed a differential annual rates of deforestation between the defined intervals of the studied period which are $0.03 \%$ from 1992 to 2001 . During the following 9 years (2001-2010) the rate has increased to $0.19 \%$ before decreasing to $0.13 \%$ from 2010 to 2015 . The average deforestation rate of the three periods is estimated to $0.11 \pm 0.08 \%$ /year, while the overall annual rate of the studied period (1992-2015) is $0.09 \%$, which are globally a slow rate.

\subsection{Drivers of Deforestation}

Deforestation implies a long-term or permanent loss of forest cover and its transformation into another land use. There are a multitude of drivers that can be classified into two categories: direct and indirect. At the local level the drivers of deforestation are subjected to complex interactions with short or long-term impacts. Figure 5 summarizes the main drivers and their probable impacts in the study area.

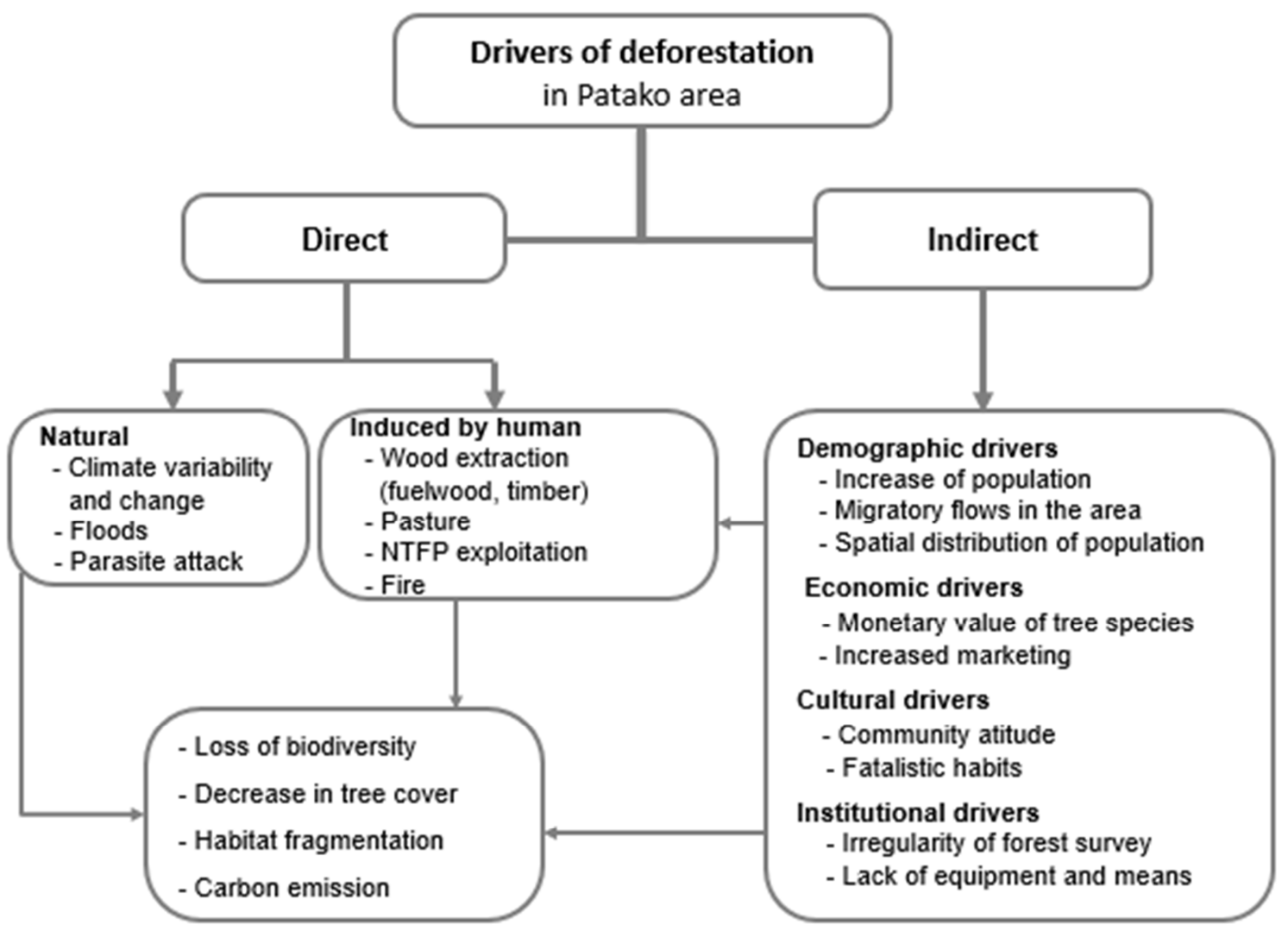

Figure 5. Drivers of deforestation in and around Patako protected area.

The localities around the protected area did not have the same impact on forest degradation. Villages of both sides within a radius of $3 \mathrm{~km}$ were grouped into four locations. Those located in the western, northern and southern parts of Patako protected area had more facilities for access than the eastern part. This has resulted by an increase of the deforestation front line. Djikoye river is a natural barrier that reduced the flow of forest operators from the eastern side. The nearest protected area of Baria played an important role in meeting fuelwood and pasture for local communities.

\section{Discussion}

\subsection{Land Use-Land Cover from 1992 to 2015}

The supervised classification approach resulted in good classification. The HV category presented both dense trees, thickets and aquatic invasive species (Typha domingensis and ferns). Pixels falling into this mixed category of vegetation had high similarity in spectral signature and were difficult to discriminate. It have been reported that 
degraded forest may be difficult to distinguish from certain types of grassland [22, 23-24]. Such difficulties arise particularly in wetlands and riparian areas $[25,26]$. The 30 $\mathrm{m}$ resolution of images used may be a limit in spatial analysis and can influence the accuracy of the classification of small areas. Therefore field visits are invaluable to avoid lousy visual interpretation of images.

The LULC maps showed a progressive increase in land under cultivation over the years of study. The results have shown a rapid evolution of WS between 1992 and 2010. In 2001, the observed extend of this category might be explained by different phonological process of some species. In the other hand, this may be as a result of increased precipitation in 1999 and 2000 in the sudanian zone compared to earlier years. An increase of grass cover was also observed at the expense of the SSS. This category included areas currently under crop and land under preparation. In 2010 and 2015, it was highly difficult to discriminate GS in the agrosystem area because of the agricultural practices. Famers used to apply one time of weed control to avoid competition with grass until a certain height of millet crops. As for peanut cultivation, they usually weed two times and export straw after harvest (food for livestock). Such practices show a character of bare soil during the dry season.

\subsection{Dynamics of Land Use-Land Cover Change}

Land use and land cover changes (LULCC) are complex processes involving multiple driving forces that are location specific and context dependent. This complexity becomes even more important that the interactions between direct, indirect and underlying drivers are dominated by anthropogenic activities or influences.

Significant changes in the LULC have been observed in the agrosystem and within the protected area during the period 1992-2015. Some categories have been systematically transformed in varied proportions. These transformations concerned mainly land conversion. This type of change, from SSS or GS to CP, was quite intense and common in the studied landscape. Indeed, since the 1970s, many protected areas in the sudanian zone of Senegal have known an important spatial and temporal dynamics [12]. However, despite the human pressure agricultural incursion within the protected area was negligible. In other hand land modification affected $\mathrm{HV}$, WS, SSS and SS, but these changes can be subtle [18]. Some authors supported that a detailed analysis of spatial dynamics allows a better knowledge of human activities impact on habitats [27, 28]. Changes resulting from land use are generally complex and contributes to alter natural habitats. [29] described this alteration as leading to the establishment of a mosaic of savanna in Patako protected area.

Changes affected mostly the periphery of the protected area. It has been shown that almost all lands in the agrosystem were cultivated in 2010. An important increase of land converted to agricultural land was observed, which supports earlier studies from 1972 to 2002 [30]. These changes resulted from an intensification of the use of animals for cultivation during many years ago in the Groundnut Basin. We argued that such increasing trend of agricultural production was to fulfill growing food demand and commercial opportunities. The cultivation techniques used promote land clearing. Likewise, canopy fragmentation had an impact on diameter structure its opening led to tree density decreasing and habitat fragmentation [31, 32]. Combining field observations of tree cover, height and diameter structure helped to characterize subtle changes in land cover.

\subsection{Rate of Land Cover Change}

In the study area, the combination of drivers led to a fast rate of land cover change. These drivers constituted a wide variety of human activities including climate variability and change. The most affected vegetation types in Patako protected area were HV and WS. This could be related to the types of species exploited in these categories, mainly largediameter trees for timber (Khaya senegalensis, Daniellia oliveri, Pterocarpus erinaceus and Cordyla pinnata). However, the SSS have been increasing after two decades despite of its serious modification at the middle and the northeast. Knowing how and why forest area changes over time is important for managing forests sustainably because such changes may result in long-term forest conversion to agriculture. From 1992 to 2015 the current study found an annual rate of deforestation which is globally very low compared to that estimated in the whole of Senegal by [1], approximately for the same period $(0.47 \%$ annually $)$. Compared to the protected area the agrosystem has a slightly higher rate of deforestation as estimated by [14]. Nowadays, this area is dominated by a low tree density of Cordyla pinnata with aging population. Indeed, such aged stands of trees increased the vulnerability to fire and an absence of natural regeneration recruitment.

\subsection{Drivers of Deforestation}

This section reviews some of the most important drivers of deforestation that are either direct or indirect. Some direct drivers are natural. It is the case of climate variability and change and its repercussions on wetlands. Since the 70s, as other Sahelian countries in West Africa, Senegal has experienced a long period of rainfall deficits that affected natural ecosystems. Mean rainfall decreased by $20-49 \%$ between the periods $1931-1960$ and $1968-1997$ [33]. The declining rainfall has modified the hydrological regime of the rivers around Patako protected area. This change has resulted in the development of vegetation in the riverbeds. However, since the early 2000s there has been an increase in rainfall despite a sharp intermonth and interannual variability.

Floods became a cause of tree mortality in the valleys. It was perceived that the number of flood events has been increased on average from less than 2 per year before 1990 to more than 10 during the 2000s [34]. The deposits of organic matter and silt drained by the water favored the establishment of an invasive perennial herbaceous plant (Typha 
domingensis). This invasive species has an important asphyxiating power that inhibits the development of other species. Such ecological conditions increased tree mortality along the river banks and created small openings on the canopy.

Parasite attacks, although weakly expressed are not negligible for describing natural drivers of deforestation. The genus Tapinanthus is the most common and often lead to tree mortality in the study area. As observed by [35], the susceptibility for trees to be infested was aided by senescence, fissure of bark and decrease of ability for resistance. This phenomenon is common in the local area where the Cordyla pinnata parkland consists of aging population.

An important part of direct drivers of deforestation was determined by human activities such as wood extraction, pasture, NTFP exploitation and the use of fire. Agricultural expansion was the main driving force of deforestation in the periphery. Contrary to the agrosystem, this problem is mostly dominated, in the core protected area, by wood harvesting which is driven by illegal logging.

Wood extraction has been demonstrated as one of the strong drivers of deforestation in the study area. The surrounding communities use wood as a primary source of energy for cooking. Unlike fuelwood, charcoal usually comes from trunks or large limbs and requires cutting trees. Even if charcoal may not always be the primary driver of deforestation, it can contribute significantly to degradation and destruction of the vegetation strata that have already been disturbed. As for the timber woods, there is a selective logging both among species and individuals into a cohort of one species. It was supported that this practice constituted a major agent of landscape modification due to the intensity use of machines for illegal timber extraction [36]. The most threatened species in the savanna formations in relation to wood timber extraction are Pterocarpus erinaceus, Cordyla pinnata, Bombax costatum, etc. By cons, in the HV, Khaya senegalensis is abusively exploited due to the economic value of its wood. Even if proximity to Patako protected area is determinant in considering the problem of deforestation, it has been perceived that people engaged in illegal activities are mostly non-residents. Indeed, beyond the satisfaction of the local market in furniture, the attraction is also due to supply some fisheries areas for making boats.

These types of forest exploitation has been documented as a problem in many rural areas in Africa [37, 38-39, 40]. [41] considered wood extraction for fuelwood and timber as contributing to forest degradation even without significant changes especially when the initial area was well bordered. As stated by [42] continuous and/or widespread human impacts can lead to vegetative changes. The damages can be an irreversible loss of species and carbon stock. Indeed, repeated actions of tree cutting and overgrazing resulted in open savanna types (SSS and DSS) with a significant frequency of stumps and cut tree stems. These elements have been considered as a key indicator of forest degradation [43, 44-45]. The presence of several tracks on any direction in
Patako protected area illustrated the pressure level on natural vegetation, as it has been shown in other protected areas in the region [46].

Human pressure was also manifested by the incursion of the Fulani transhumant pastoralists during the dry season. This incursion was considered a driving force behind degradation because requiring a significant animal load. The environmental problems caused by overgrazing in Patako area are the destruction of vegetation and soil erosion.

The predominant motivation of actors in NTFP harvesting is the quest for income generation. Exudates from plants mainly such as resins are processed to give local communities added value in the marketplace. As an example, human pressure on the perfumes products of Daniellia oliveri was manifested by unsustainable practices of harvesting. Other activities such as the use of plants (leaves, barks, roots) in traditional medicines can be a source of deforestation or degradation because they become more vulnerable to fire.

Unsustainable practices of forest exploitation are often a key variable of annual fire regimes in Patako area. Here, fires are caused accidentally or simply used by forest operators to burn grasses in order to facilitate access during the dry season. Even if its impact was considered negligible on adult trees [47], fire is one of the significant driving force in the dynamics of savannas $[48,49]$.

Indirect drivers contributed mostly to increase deforestation in Patako area. Four categories of indirect drivers were described: demographic, economic, cultural and institutional.

Rapid growth in population and increase of socioeconomic needs implied a cumulative pressure on forest resources. The study area recorded also an important flow of migration due to space availability and social context. This context explained the spatial distribution of land use [50]. National agricultural policies in the 1960s and 1970s encouraged farmers to clear their fields of most trees to facilitate crop planting and harvesting. Then, trees density and diversity has declined as well because of the use of animal traction technologies for cultivation.

The economic value of some species used for timber and fuelwood has dramatically increased in recent years because of the local and external strong demand. In fact, the creation of weekly markets in areas around a radius of $8 \mathrm{~km}$ from the border of the protected area opened increasingly a way to fraudulent and opportunistic exploitation of forest resources. Some villages have a major advantage due to the presence of fertile valleys with fresh water, a favourable framework for market gardening. Other ones, where this opportunity did not exist people developed logging activities to supply economic needs in dry season. In this context, [51] considered the existence of the communities in many surrounded villages as closely linked to the use of forest resources.

Cultural drivers can be catalysts that influence flows entering into the protected areas. A significant part of the informants considered the natural resources in the protected area as belonging to local people. This representation has led to attitudes hardly compatible with a sustainable management 
of forest resources [51].

The institutional drivers of deforestation are multiform and complex. Two technical agents were mandated by the Forest Service for managing the Patako protected area. However, they are frequently faced with a problem of logistics and the fact their service is $22 \mathrm{~km}$ far from the site of intervention, justify the irregularities on forest survey. The lack of close monitoring paved the way for fraudulent exploitation. The consequence is that savannas support two weights (anthropogenic pressure and devastation caused by fires) causing a constant spatial dynamics. Underlying drivers must be treated with cautious because they have a cumulative effect on forest resource.

\section{Conclusion}

In this study, the combination of direct and indirect anthropogenic drivers has demonstrated the complexity of land cover change analysis. The results have shown significant changes in land use-land cover for more than two decades (1992 to 2015). These changes are characterized by two main situations which are either an increase or a decrease in the area of the specified classes. Within the Patako protected area, the rate of change varied from one type of land use to another. Globally, the area of HV and WS declined due probably to the selective logging of some species exploited for their wood timber. These species are subjected to a covetousness and constitute one of the main causes of the loss in vegetable cover. The SSS has experienced a small extension of its area despite some fragmentations in stands. The persistence of this fragmentation has contributed to the emergence of the SS which is a key indicator of human pressure. Some limitations have been shown using Landsat images of medium spatial resolution for discriminating riparian tree vegetation to invasive aquatic grasses. Detecting all stages of degradation was difficult because the scale at which the degradation takes place is often at sub-pixel resolution. This means that the nature of the degradation affects areas smaller than the detection capability of the remotely sensed pixel. So mapping land cover change can introduce substantial errors in data processing and interpretation. To avoid inappropriate interpretation a generic name HV (humid vegetation) was given to this land cover instead of gallery forest. In the agrosystem the rate of land cover change was high because of the agricultural practices. To solve the problem of deforestation, a reforestation project has been implemented in a participatory way with rural communities. The main goal was to create a buffer zone by restoring plant biodiversity in order to reduce the pressure on the protected area for which in spite of a low rate of deforestation experienced many modifications.

\section{Acknowledgements}

The authors are grateful to UNDESERT Program (www.undesert.neri.dk) for the financial support.
UNDESERT (EU FP7 243906), "Understanding and combating desertification to mitigate its impact on ecosystem services" is funded by the European Commission, Directorate General for Research and Innovation, Environment Program. We acknowledge the Department of Bioscience of Aarhus University (Denmark) for the collaboration.

\section{References}

[1] FAO, 2010. Global Forest Resource Assessment. Food and Agriculture Organization of the United Nations (Ed.), Rome, pp. 378 .

[2] Houghton, R., 2012. Carbon emissions and the drivers of deforestation and forest degradation in the tropics. Current Opinion in Environmental Sustainability 4, 1-7.

[3] Hansen, M.C., Potapov, P.V., Moore, R., Hancher, M., Turubanova, S.A., Tyukavina, A., Thau, D., Stehman, S.V., Goetz, S.J., Loveland, T.R., Kommareddy, A., Egorov, A., Chini, L., Justice, C.O., Townshend, J.R., 2013. Highresolution global maps of 21 st-century forest cover change. Science 342, 850-853.

[4] Huang, B., Babcock, H., Zhuang, X., 2010. Breaking the diffraction barrier: super-resolution imaging of cells. Cell 143, $1047-1058$

[5] Hansen, J., Ruedy, R., Sato, M., Lo, K., 2010. Global surface temperature change. Reviews of Geophysics 48, 1-15.

[6] Kadioğullari, A.İ., Sayin, M.A., Çelįk, D.A., Borucu, S., Çįl, B., Bulut, S., 2014. Analysing land cover changes for understanding of forest dynamics using temporal forest management plans. Environmental Monitoring and Assessment 186, 2089-2110.

[7] FAO, 2005. Global Forest Resource Assessment 2005. Food and Agriculture Organization of the United Nations (Ed.), Forestry Papers. Rome, pp. 147.

[8] Mbow, C., Nielsen, T.T. Rasmussen, K., 2000. Savanna fires in East-Central Senegal: distribution patterns, resource management and perceptions. Human Ecology 28, 561-583.

[9] Mbow, C., Nielsen, T.T., 2009. Senegal case study. SAFNet, Africa environment outlook case studies: impacts of fires on the environment (UNEP and SARDC). Nairobi-Kenya, UNEP-AEO: 48.

[10] Brink, A.B., Eva, H.D., 2009. Monitoring 25 years of land cover change dynamics in Africa: a sample based remote sensing approach. Applied Geography 29, 501-512.

[11] Clevers, J., Bartholomeus, H., Müchers, S., de Witt, A., 2004. Land cover classification with the Medium Resolution Imaging Spectrometer (MERIS). EARSeL eProceedings 3.

[12] Tappan, G.G., Sall, M., Wood, E.C., Cushing, M., 2004. Ecoregions and land cover trends in Senegal. Journal Arid Environment 59, 427-462.

[13] Mbow, C., Mertz, O., Diouf, A., Rasmussen, K., Reenberg, A., 2008. The history of environmental change and adaptation in Eastern Saloum, Senegal: driving forces and perceptions. Global and Planetary Change 64, 210-221. 
[14] Christensen, S.N., 2010. Socio-economic and ecological determinants of local scale tree distribution, diversity and dynamics in agro ecosystems in West-central Senegal. Master thesis, Aarhus University, $19 \mathrm{p}$.

[15] Hammi S, Simonneaux V, Alifriqui M, Auclair L, Montes N, 2007. Evolution des recouvrements forestiers et de l'occupation des sols entre 1964 et 2002 dans la haute vallée des Ait Bouguemez (Haut Atlas central, Maroc). Sécheresse 18: 271-7.

[16] Aubreville A, 1957. Accord de Yangambi sur la nomenclature des types africains de vegetation. Bois et Forets des Tropiques 51:23-7.

[17] De Wispelaere G, 2002. Cartographie de la végétation du complexe du « W ». Montpellier: Cirad editions.

[18] Lambin, E.F., Geist, J.H., Lepers, E., 2003. Dynamics of landuse and land-cover in tropical regions. Annual Review of Environmental Resources 28, 205-241.

[19] Sambou, H., Sambou, B., Diaw, A.T., Mbow, C., Traore, V., 2014. Remote Sensing Mapping of the Rice Field and Vegetal Cover and the Impacts of Soil Factors on Herbaceous in the Sub-Watershed of Boutolate (Lower Casamance, Senegal). American Journal of Environmental Protection, 3, 73-82.

[20] FAO, Food and Agriculture Organization (2007). Manual On Deforestation, Degradation, And Fragmentation Using Remote Sensing And GIS. Strengthening Monitoring, Assessment and Reporting on Sustainable Forest Management In Asia. Food and Agriculture Organization of the United Nations. Working Paper No. 5. Italy Rome.

[21] Puyravaud, J.P., 2003. Standardizing the calculation of the annual rate of deforestation. Forest Ecology and Management $177,593-596$.

[22] Jezching, T., Sticklen, J., Jain, A.K., 1991. Knowledge-based segmentation of Landsat images. IEEE Transactions on Geoscience and Remote Sensing: 222-232.

[23] Foody, G.M., 2002. Status of land cover classification accuracy assessment. Remote Sensing of Environment 80, 185-201.

[24] Hansen, M.C., Roy, D.P., Lindquist E., Adusei, B., Justice, C.O., Altstatt, A., 2008. A method for integrating MODIS and Landsat data for systematic monitoring of forest cover and change in the Congo Basin. Remote Sensing of Environment $112,2495-2513$.

[25] Corey, B., Lawrence, R., Montagne, C., Patten, D., 2006. Mapping wetlands and riparian areas using Landsat ETM+ imagery and decision-tree-based models. Wetlands 26, 465474.

[26] Gong, P., Wang, J., Le, Y., Zhao, Y., Zhao, Y., 2013. Finer resolution observation and monitoring of global land cover: first mapping results with Landsat TM and ETM+ data. International Journal of Remote Sensing 34, 2607-2654.

[27] Hepinstall, J.A., Sader, S.A., 1997. Using Bayesian statistics, thematic mapper satellite imagery, and breeding bird survey data to model bird species probability of occurrence in Maine. Photogrammetric Engineering and Remote Sensing 63, 12311237.

[28] Sperduto, M.B., Congalton, R.G., 1996. Predicting rare orchid (small whorled Pogonia) habitat using GIS. Photogrammetric Enginnering and Remote Sensing 62, 1269-1279.
[29] Mbow, C., Chhin, S., Sambou, B., Skole, D., 2013. Potential of dendrochronology to assess annual rates of biomass productivity in savanna trees of West Africa. Dendrochronologia 31, 41-51.

[30] Guiro, I., Mbow, C., Baret, F., Diaw, A.T., 2012. Dynamique de l'occupation du sol de la forêt classée de Patako et de sa périphérie de 1972 à 2002. Revue de Géographie du Laboratoire Leïdi 10, 257.

[31] Curran, L.M., Trigg, S.N., McDonald, A.K., Astiani, D., Hardiono, Y.M., Siregar, P., Kasischke, E., 2004. Lowland forest loss in protected areas of Indonesian Borneo. Science $303,1000-1003$.

[32] Fischer, J., Lindenmayer, D.B., 2007. Landscape modification and habitat fragmentation: a synthesis. Global Ecology and Biogeography 16, 265-280.

[33] Dore, M.H.I., 2005. Climate change and changes in global precipitation patterns: What do we know? Environment International 31, 1167-1181.

[34] Sarr, B., 2011. Return of heavy downpours and floods in a context of changing climate. Climate change in the Sahel. A challenge for sustainable development. AGRHYMET Monthly Bulletin (Special issue), pp, 9-11.

[35] Edagbo, D.E., Ajiboye, T.O., Borokini, T.I., Ighere, D.A., Alowonle, A., Michael, C., 2013. A study of the conservation status of Citrus sinensis as affected by the African Mistketoe, Tapinanthus bangwensis in Moor plantation, Ibadan, SouthWest, Nigeria. International Journal Current Agricultural Sciences 3, 5-9.

[36] Mon, M.S., Mizoue, N., Htun, N.Z., Kajisa, T., Yoshida, S., 2012. Factors affecting deforestation and forest degradation in selectively logged production forest: a case study in Myanmar. Forest Ecology and Management 267, 190-198.

[37] Madubansi, M., Shackleton, C.M., 2006. Changing energy profiles and consumption patterns following electrification in five rural villages, South Africa. Energy Policy 34, 40814092.

[38] Van der Plas R.J., Ali Abdel-Hamid, M. 2005. Can the woodfuel supply in sub-Saharan Africa be sustainable? The case of N'Djamena, Chad. Energy Policy 33, 297-306.

[39] Ndayambaje, J.D., Mohren, G.M.J., 2011. Fuelwood demand and supply in Rwanda and the role of Agroforestry. Agroforestry Systems 83, 303-320.

[40] Hiemstra-van der Horst, G., Hovorka A.J., 2009. Fuelwood: the other renewable energy source for Africa? Biomass and Bioenergy 33, $1605-1616$.

[41] Shi, M., 2008. Literature Review : Changes and feedbacks of land-use and land-cover under global change $15 \mathrm{pp}$.

[42] Lykke, A.M., 1998. Assessment of species composition change in savanna vegetation by means of woody plants size class distributions and local information. Biodiversity and Conservation 7, 1261-1275.

[43] Lambin, E.F., 1999. Monitoring forest degradation in tropical regions by remote sensing: some methodological issues. Global Ecology and Biogeography 8, 191-198. 
[44] Frasera, E.D.G., Dougilla, A.J., Mabeeb, W.E., Reeda, M., McAlpine, P., 2006. Bottom up and Top down: Analysis of participatory processes for sustainability indicator identification as a pathway to community empowerment and sustainable environmental management. Journal of Environmental Management 78, 114-127.

[45] Kotwal, P.C., Kandari, L.S., Dugaya, D., 2008. Bioindicators in sustainable management of tropical forests in India. African Journal of Plant Science 2, 99-104.

[46] Tappan, G.G., Hadj, A., Wood, E.C., Lietzow, R.W., 2000. Use of argon, corona, and landsat imagery to assess 30 years of land resource changes in West-central Senegal. Photogrammetric Engineering and Remote Sensing 66, 727736.

[47] Lloret, F., Estevan, H., Vayreda, J., Terradas, J., 2005. Fire regen- erative syndromes of forest woody species across fire and climatic gradients. Oecologia 146, 461-468.

[48] Sow, M., Mbow, C., Hély, C., Fensholt, R., Sambou, B., 2013. Estimation of herbaceous fuel moisture content using vegetation indices and land surface temperature from MODIS data. Remote Sensing 5, 2617-2638.

[49] Mbow, C., Goïta, K., Bénié, G.B., 2004. Spectral indices and fire behavior simulation for fire risk assessment in savanna ecosystems. Remote Sensing of Environment 91, 1-13.

[50] Uneke, C., 2009. Deforestation and malaria in sub-Saharan Africa: an overview. The Internet Journal of Tropical Medicine 6, 1.

[51] Diop, M., Sambou, B., Goudiaby, A., Guiro, I., Niang-Diop, F., 2011. Ressources végétales et préférences sociales en milieu rural sénégalais. Bois et Forêts des Tropiques 4, 57-68. 